\title{
Stress, cortisol and reproduction in female pigs
}

\author{
A.I. Turner and A.J. Tilbrook \\ Department of Physiology, PO Box 13F, Monash University, VIC 3800, Australia
}

\begin{abstract}
Two key hypotheses emerge in the literature regarding the impact of stress on reproduction in females of any species. First, prolonged stress impairs reproduction in females. Secondly, acute stress impairs reproduction, if it occurs at a critical time during the precisely timed series of endocrine events that induce oestrus and ovulation. We reviewed studies conducted in female pigs to find support or opposition for these hypotheses in female pigs. We also considered the role of cortisol. We found confirmation that prolonged stress or the prolonged elevation of cortisol can impair reproductive processes in female pigs, but also found that there appear to be some female pigs in which reproduction is resistant to such treatments. Reproduction in female pigs appears to be resistant to acute or repeated acute stress or elevation of cortisol, even if these occur during the series of precisely timed endocrine events that induce oestrus and ovulation. Thus, we propose modified versions of the above hypotheses that are specific to female pigs. Furthermore, while cortisol may mediate the effects of prolonged stress on reproduction in female pigs, there is evidence that, in female pigs, ACTH may require the presence of the adrenal glands to impair reproduction rather than having direct effects.
\end{abstract}

\section{What is stress?}

Stress is a difficult term to define and, consequently, many different definitions have been proposed (Munck et al., 1984; Goldstein 1987; Harbuz and Lightman 1992; von Borell 1995). A commonly accepted definition is that stress is a disruption to homeostasis. Noxious stimuli that threaten homeostasis are generally referred to as stressors. These can assume many different forms including physical, psychological and physiological stressors (Dobson and Smith 1995). Stressors can be acute (lasting for seconds, minutes or up to a few hours) or prolonged (lasting for days, weeks or months).

\section{Physiological responses to stress}

Many physiological pathways are activated by stress. An immediate response to stress is activation of the sympathoadrenal system (Dalin et al. 1993a; Minton 1994), which consists of the sympathetic nervous system and the adrenal medulla. Sympathetic pathways from the centralf nervous system to a target tissue consist of preganglionic and postganglionic nerve fibres (Goldstein 1987). Preganglionic nerve fibres stimulate postganglionic nerve fibres to secrete noradrenaline in peripheral target tissue. In the case of the adrenal medulla, the preganglionic 
nerves pass directly to the adrenal medulla where they stimulate modified neuronal cells to secrete adrenaline and noradrenaline into the peripheral circulation (Goldstein 1987). Together, adrenaline and noradrenaline are referred to as catecholamines. The sympathoadrenal system is activated within seconds of an emergency being perceived, preparing the animal for a "flight or fight" response (Sapolsky et al. 2000).

Another ubiquitous response to stress is activation of the hypothalamo-pituitary adrenal axis (Dalin et al. 1993a; Minton 1994). Activation of this axis results in the release of corticotrophin releasing hormone $(\mathrm{CRH})$ and vasopressin from the hypothalamus into the hypothalamo-hypophysial portal circulation (Minton 1994; Torpy and Chrousos 1996). CRH and vasopressin are produced in parvocellular neurones in the paraventricular nucleus of the hypothalamus (Sawchenko et al. 1992; Antoni 1993; Clarke 1996). In pigs, vasopressin is secreted as lysine vasopressin, while in most other mammalian farm species, vasopressin is secreted as arginine vasopressin (Heller 1960; Minton and Parsons 1993; Minton 1994). CRH and vasopressin stimulate the anterior pituitary gland to synthesise and release adrenocorticotrophic hormone (ACTH) (Torpy and Chrousos 1996; Antoni 1993). In pigs, CRH is a more potent ACTH secretagogue than vasopressin (Minton 1994). Nevertheless, the actions of $C R H$ and vasopressin synergise (Minton 1994). After transport in the systemic circulation, ACTH induces cells located in the adrenal cortex to synthesise glucocorticoids such as cortisol (Torpy and Chrousos 1996). In pigs, the principle glucocorticoid released by the adrenal glands is cortisol. Steroids, such as cortisol, are lipid soluble and therefore, cortisol leaves the cell by readily diffusing through the plasma membrane.

Most circulating cortisol is bound to corticosteroid-binding globulin (CBG). Cortisol in this form is not biologically active. The $3-10 \%$ which is not bound (free cortisol) is biologically active and can diffuse into target cells (Torpy and Chrousos 1996). Total plasma concentrations of cortisol (bound and free) follow a diurnal rhythm with concentrations being highest early in the morning in species which are active during daylight hours (Dallman et al. 1992), including pigs Janssens et al. 1995b). Furthermore, the elevation of cortisol in response to stress is greatest during the nadir in diurnal rhythm and is lowest during its peak (Dallman et al. 1992; Janssens et al. 1995b). Glucocorticoids regulate basal and stress-induced activity of the hypothalamo-pituitary adrenal axis through negative feedback actions at the brain (Dallman et al. 1992). The hypothalamo-pituitary adrenal axis is activated within minutes of a stressor with peak plasma concentrations of cortisol being reached around 15 minutes after an acute stressor.

The elevation of circulating concentrations of adrenaline, noradrenaline and cortisol that is induced by stress results in the rapid mobilisation of the body's energy stores to allow the necessary responses to cope with the challenge encountered. For instance, adrenaline and noradrenaline result in changes, such as an increase in heart rate, dilation of the bronchial tree, an increase in pupil dilation and redistribution of blood to skeletal and cardiac muscle and away from organ systems which are not essential in a particular emergency, such as the gastrointestinal tract and kidney (Udelsman and Holbrook 1994). The actions of glucocorticoids are many and varied and include increased glycogenolysis by the liver, inhibition of the insulin-induced uptake of glucose in peripheral tissues and lipolysis in adipose tissue, all of which increase the energy available to respond to stress (Munck et al. 1984; Udelsman and Holbrook 1994). While other hormones (e.g. opioids, prolactin, insulin, triiodothyronine, thyroxine, growth hormone and insulin-like growth factor 1) are also released in response to stress in pigs (Rushen and Ladewig 1991; Farmer et al. 1991), the physiological significance of these and their role in restoring homeostasis is less clear. The extent to which the stress pathways are activated following stress depends on the stressor that is encountered.

Mostly, when faced with stress, activation of physiological stress systems is highly effective in re-establishing homeostasis and allowing coping, but prolonged activation of these systems 
can lead to a range of detrimental physiological effects (Moberg 1985a). Studies in pigs showed that prolonged exposure to stress led to impairment of growth (Hemsworth et al. 1987), compensation of the immune system (Barnett et al. 1992) and disruption of reproductive performance (see below).

\section{Why is cortisol important?}

Cortisol is the end product and principal effector hormone of the hypothalamo-pituitary adrenal axis. While any of the central and peripheral pathways activated by stress could potentially influence the physiological systems, most research has focussed on the importance of the hypothalamo-pituitary:adrenal axis and/or its components (Moberg 1985b; Moberg 1987; Moberg 1991; Clarke et al. 1992; Liptrap 1993; Dobson and Smith 1995; Tilbrook et al. 2000; Tilbrook et al. 2002; Turner et al. 2002). It is generally accepted that the hypothalamo-pituitary:adrenal axis has an important role in mediating the detrimental effects of stress on physiological systems in a range of species. Much evidence for this view has been provided by studies in which hormones of this axis were administered and various parameters measured.

Plasma concentrations of cortisol are relatively easy to measure and have been well documented, showing that the hypothalamo-pituitary:adrenal axis has a reliable and repeatable response to stress (Minton 1994). Consequently, a cortisol response is considered by many as an "indicator" of when an animal is experiencing stress. On the one hand, such an association is simplistic because cortisol is also released in response to challenges or changes that would not normally be considered "stressful", such as eating a meal (Soede et al. 1997) or mating (Barnett et al. 1982). Furthermore, as cortisol is only one of the hormones that is released in response to stress, a focus on the link between cortisol and stress can risk our overlooking involvement of other hormones that may have an important role. In support of the view that a cortisol response indicates "stress", is that prolonged elevation of cortisol in the circulation, can lead to impairment of physiological systems that are similar to those induced by prolonged stress.

The association between stress and cortisol has been utilised in many studies in female pigs where plasma concentrations of cortisol have been measured in response to various procedures, including 6 minutes of electrical stimulation (Veum et al. 1979; Becker et al. 1985), 60 minutes of confinement in a box (Becker et al. 1985), use of a snout rope (Farmer et al. 1991; Janssens et al. 1995a), transportation (Dalin et al. 1993b; McGlone et al. 1993), mixing of unfamiliar pigs for 90 minutes, relocation and surgery (Dalin et al. 1993a). It was also shown that an iv injection of $5 \mathrm{mg}$ cortisol resulted in an elevation of cortisol which was similar to that induced by an acute stressor (Dalin et al. 1993a) and a maximal plasma cortisol response was demonstrated in a study in which $10 \mathrm{mg} \mathrm{ACTH} \mathrm{(1-24)/kg} \mathrm{body} \mathrm{weight} \mathrm{was} \mathrm{administered} \mathrm{iv} \mathrm{to} \mathrm{gilts} \mathrm{(lanssens} \mathrm{et}$ al. 1994). In this latter study (Janssens et al. 1994), the authors reported that an earlier doseresponse study (unpublished) had shown that this dose of ACTH induced a maximal plasma cortisol response in gilts. The cortisol response to stress was reliable and repeatable within and between individuals and the extent of the response appears to be associated with the severity of the stressor in a graded manner.

In contrast to cortisol, very few studies have measured the adrenaline and/or noradrenaline response to stress. The most likely reasons are that the catecholaminergic response to stress is highly variable (Minton 1994) and, in relative terms, plasma concentrations of catecholamines are more difficult to measure than plasma concentrations of cortisol. While adrenaline and noradrenaline were released and subsequently cleared rapidly (seconds to a few minutes) following exposure to a stressor (Sapolsky et al. 2000), cortisol had a slower time course (many 
minutes to several hours), and therefore, is likely responsible for many of the longer term responses to stress (Sapolsky et al. 2000).

\section{Successful reproduction relies on a series of precisely timed endocrine events}

Reproduction in the female is controlled by a series of hormonal interactions between the brain, anterior pituitary and ovary. Collectively, these interactions are termed the hypothalamopituitary:ovarian axis. Neurones in the hypothalamic region of the brain synthesise and secrete the decapeptide, gonadotrophin releasing hormone $(\mathrm{GnRH})$. In the pig, the largest proportion of $\mathrm{GnRH}$ neurones are located in the medial preoptic area and the GnRH neurones, which are involved in regulation of reproduction, project to the median eminence (Kineman et al. 1988). At this point, $\mathrm{GnRH}$ is released into the hypophyseal portal blood system in a pulsatile manner (for review see Kraeling and Barb 1990). GnRH stimulates the anterior pituitary to synthesise and release the gonadotrophins, luteinising hormone $(\mathrm{LH})$ and follicle stimulating hormone (FSH). LH and FSH are transported in the systemic circulation to the ovaries where their primary functions are to stimulate development of germ cells and synthesis of ovarian hormones, including sex steroids and the glycoprotein, inhibin. The predominant sex steroids produced by the ovary are progesterone and oestrogen.

Successful reproduction in female pigs is dependent on the hormonal interactions of the hypothalamo-pituitary:ovarian axis being precisely synchronised with key behavioural and physiological events. These endocrine, behavioural and physiological interactions occur on a regular cyclical basis that is termed the oestrous cycle. In pigs, duration of the oestrous cycle is about 21 days (Hughes et al 1996). Most of the oestrous cycle is marked by the luteal phase where progesterone and oestrogen are secreted in substantial amounts and exert strong negative feedback actions on the hypothalamo-pituitary unit. This is followed by the follicular phase where oestrogen, in the absence of progesterone, initially exerts weak negative feedback actions that switch to positive feedback during the late follicular phase (Esbenshade et al. 1990; Zeleznik and Hillier 1996). The consequent elevation in the secretion of oestrogen induces the period of sexual receptivity that is a hallmark of oestrous behaviour (Beach 1976) and surges in the secretion of $\mathrm{LH}$ and FSH that induce ovulation (Foxcroft and Van de Wiel 1982). It is crucial that induction of oestrous behaviour and ovulation occur with suitable timing to allow females to mate when conditions are optimal for fertilisation to ensue. Thus, disruption of any of the events of the oestrous cycle, or the timing of these events, has the potential to disturb reproduction.

\section{Can stress impair reproduction?}

There are two key hypotheses that emerge in the literature regarding the impact of stress on reproduction in females of any species. First it is generally agreed that prolonged stress impairs reproduction in females (Coubrough 1985; Moberg 1985b; Moberg 1987; Moberg 1991; Clarke et al. 1992; Liptrap 1993; Varley and Stedman 1994; Dobson and Smith 1995; Tilbrook et al. 2000; Tilbrook et al. 2002; Turner et al. 2002). Second, reproduction in females is particularly vulnerable to the effects of acute stress during the series of endocrine events leading to oestrus and ovulation (Moberg 1985b; Varley and Stedman 1994). The basis for this is that an acute stressor at a critical time during the series of endocrine events of the late follicular phase may disrupt the subsequent events, including oestrus and ovulation and, possibly, fertilisation and the establishment and maintenance of pregnancy. If acute stress can impair reproduction, exposure to repeated acute stress would increase the likelihood that an acute stressor may occur at 
a critical time. Furthermore, acute stress or repeated acute stress may have the greatest impact on reproduction during the late follicular phase due to the need for maximal concentrations of oestrogens for oestrus and induction of the preovulatory $\mathrm{LH}$ surge at this time. In rats, there is evidence that oestrogens facilitate and androgens inhibit the activity of the hypothalamopituitary:adrenal axis (Da Silva 1995). The influence of oestrogens on the activity of the hypothalamo-pituitary:adrenal axis in female pigs is not known but, if oestrogens have a facilitatory effect as in the female rat, the pre-ovulatory surge of oestrogen and the events which depend on it (oestrus, the LH surge and ovulation) may be particularly prone to the effects of acute stress.

The following sections review the relevant literature regarding whether or not the hypotheses stated above apply in female pigs. Thus, we will consider the impact of prolonged, acute or repeated acute stress or prolonged, acute or repeated acute elevation of cortisol on reproduction in female pigs.

\section{Prolonged stress or elevation of cortisol}

\section{Stress}

Reproduction in female pigs can be impaired by exposure to stress that is severe and prolonged. Nevertheless, even under these circumstances, it appears that reproduction in some individuals may be resistant to the effects of prolonged stress. Factors associated with intensive pig production, which can expose female pigs to prolonged stress, include social environment (i.e. number housed together in a pen), stocking density (i.e. area of floor space per pig), housing systems (i.e. tethers versus stalls versus group housing), human-animal interactions (i.e. fear of the stockpersons) (Varley and Stedman 1994) and social rank (i.e. dominant versus subordinate hierarchy position) (Arey and Edwards 1998). The following are examples of studies that have imposed prolonged stress on female pigs and considered the effects on reproductive performance.

Gilts were housed in crowded $\left(1 \mathrm{~m}^{2}\right.$ per gilt) or uncrowded ( $3 \mathrm{~m}^{2}$ per gilt) conditions for 21 days (Hemsworth et al. 1986b). Plasma concentrations of free cortisol were higher in crowded than uncrowded gilts and fewer crowded than uncrowded gilts were detected in oestrus (30/34 versus $34 / 34$, respectively) and mated ( $26 / 34$ versus $33 / 34$, respectively). Overcrowding did not affect any other measures of sexual receptivity. While this study confirms that prolonged stress can impair reproductive performance in female pigs, it shows that oestrus, in 30 gilts, and mating, in 26 gilts, were unaffected by exposure to this stressor. Clearly, reproduction in these gilts was resistant to the prolonged stressor of living in crowded conditions.

In another study, gilts were exposed to an "unpleasant" handling treatment, which involved application of a battery-operated stock moving prod, 3 times per week beginning at 11 weeks of age (Hemsworth et al. 1986a). During this same period, another group of gilts was exposed to a "pleasant" handling treatment that involved gentle stroking. At 20 weeks of age, plasma concentrations of free cortisol were higher in unpleasantly handled gilts than in pleasantly handled gilts. After mating at second oestrus, 7 out of 8 pleasantly handled gilts became pregnant, while only 3 out of 9 unpleasantly handled gilts became pregnant. Despite the lower pregnancy rate in unpleasantly handled gilts, these gilts were similar to pleasantly handled gilts in their age at puberty, duration of oestrus and in all other measures of sexual receptivity and mating success. This study also confirms that prolonged stress can impair reproductive performance in female pigs, but shows that reproduction in 3 gilts exposed to the unpleasant handling treatment was resistant to this prolonged stress.

Housing gilts in tether stalls resulted in a smaller proportion of gilts becoming pregnant after mating (31/47) compared to housing gilts in groups (30/35) (Barnett and Hemsworth 1991). 
These authors previously showed that plasma concentrations of free cortisol were higher in gilts housed in tether stalls compared to gilts housed in groups (Barnett et al. 1985). Gilts housed in tethers were also more restless during mating than gilts housed in groups, but there were no differences between tether housed and group housed gilts in oestrous behaviour, mating success or litter size (Barnett and Hemsworth 1991). Therefore, while housing gilts in tether stalls can impair reproductive performance of the herd as a whole, reproduction in 31 gilts in this study, was resistant to the negative effects of this prolonged stressor. Another study reported that duration of oestrus was shorter in sows that were housed in tethers $(42 \pm 4 \mathrm{~h})$ compared to loose-housed sows $(63 \pm 2 \mathrm{~h})$, but there were no differences between these groups in duration of ovulation, ovulation rate, fertilisation rate, embryo development, embryo diversity or in peri-ovulatory profiles of oestradiol, LH and progesterone (Soede et al. 1997). Cortisol profiles after feeding and adrenal weights were also similar in sows in both groups, but tethered sows spent more time performing stereotypic behaviours than loose-housed sows (Soede et al. 1997). Thus, despite housing in tethers impairing expression of oestrus, the lack of difference between the groups in subsequent reproductive outcomes, such as ovulation rate, fertilisation rate and embryo development, suggests that fertility was not reduced due to tethering.

It is apparent from these studies that exposure to stress must be severe and prolonged before reproduction in female pigs is impaired. Even under these circumstances, there was great variation between individuals in vulnerability to the detrimental effects of stress, with reproduction in some individuals appearing to be resistant to prolonged stress. Furthermore, mild disruption of individual reproductive measures in female pigs did not necessarily lead to impairment of subsequent reproductive outcomes.

\section{Cortisol}

There have been many studies in female pigs in which administration of glucocorticoids, which resulted in the sustained elevation of glucocorticoids, led to impairment of reproductive parameters. For example, treatment with glucocorticoids blocked, delayed and/or shortened oestrus (Liptrap 1970; Esbenshade et al. 1983; Turner et al. 1999b), blocked ovulation (Schilling and von Rechenberg 1973; Scholten and Liptrap 1978; Barb et al. 1982; Esbenshade et al. 1983; Frautschy and Liptrap 1988; Turner et al. 1999b) and blocked the pre-ovulatory surges of oestrogen (Frautschy and Liptrap 1988) and LH (Barb et al. 1982; Turner et al. 1999b). In ovariectomised pigs, treatment with glucocorticoids inhibited basal secretion of LH (Frautschy et al. 1989; Estienne et al. 1991; Turner et al. 1999a) and blocked the oestrus (Esbenshade et al. 1983; Paterson et al. 1983) and LH surge (Paterson et al. 1983), which are normally induced by oestrogen.

In one of our studies (Turner et al. 1999a), a treatment was included (based on that of Barb et al., 1982) to elevate plasma concentrations of cortisol in a sustained manner. Cortisol was injected im resulting in elevations of plasma concentrations of cortisol constantly to around 75$100 \mathrm{ng} / \mathrm{ml}$. Four days of this cortisol treatment in ovariectomised pigs had no effect on secretion of $\mathrm{LH}$, however, by the 8th day of treatment, mean plasma concentrations of LH decreased in the absence, but not in the presence of treatment with oestradiol (Turner et al. 1999a). This study indicates that cortisol needs to be elevated for a substantial period to impair reproductive parameters. It also indicates that oestradiol did not exaggerate the suppressive effects of cortisol treatment on reproduction, as may have been expected, but possibly even provided a protective effect.

There may also be individual variation in the vulnerability of reproduction in female pigs to administration of glucocorticoids with reproduction in some female pigs being resistant to such treatment. Of 6 gonad intact gilts receiving the same sustained cortisol treatment described 
above, 3 gilts were infertile due to suppressed oestrus and ovulation, 2 other gilts displayed oestrus and ovulated, but these were delayed and diminished, and the remaining gilt was unaffected by treatment (Turner et al. 1999b). In this remaining gilt, plasma concentrations of cortisol were similar to those of the other gilts in her treatment group (i.e. around 75-100 ng/ $\mathrm{ml}$ ), but her $\mathrm{LH}$ surge, oestrous behaviour and ovulation rate were not different from those of control gilts (Turner et al. 1999b).

These studies suggest that cortisol needs to be elevated in a sustained manner for a substantial period (greater than 4 days) before reproduction is affected and, even then, reproduction in some individuals appears resistant to its effects. Elevations of cortisol, such as these would be unlikely to occur in response to severe prolonged stressors under physiological circumstances.

\section{What about ACTH?}

Administration of ACTH also disrupts reproduction in female pigs. The effects of treatment with ACTH on reproduction are similar to those reported above following treatment with glucocorticoids. For instance, treatment with ACTH blocked, delayed and/or shortened oestrus (Liptrap 1970; Barb et al. 1982; Hennessy and Williamson 1983), blocked ovulation (Liptrap 1970; Liptrap 1973; Schilling and von Rechenberg 1973; Close and Liptrap 1975; Barb et al. 1982; Hennessy and Williamson 1983), delayed the pre-ovulatory surge of oestrogen (Liptrap 1970) and blocked or delayed the pre-ovulatory surge of LH (Barb et al. 1982; Hennessy and Williamson 1983). Nevertheless, there is evidence in pigs that ACTH may not have direct actions to disrupt reproduction, but rather the actions of ACTH are mediated by the adrenal glands. For instance, when adrenalectomised and/or ovariectomised pigs were treated with ACTH, the increase in serum concentrations of LH that normally follows ovariectomy was only blocked when the adrenal glands were intact (Fonda et al. 1984). These results suggest that the inhibitory actions of ACTH on the secretion of $\mathrm{LH}$ were mediated by the adrenal glands. Similarly, Liptrap (1973) found that treatment with ACTH blocked ovulation and induced cystic follicles in adrenal intact sows, but not in a sow that was adrenalectomised. Examination of the ovaries of the adrenalectomised sow revealed that ovulation had occurred and there was no evidence of cystic follicles despite this sow having been treated with ACTH (Liptrap 1973). These findings were also supported by an in vitro study, which showed that the ability of pituitary cells from prepubertal pigs of unspecified sex to secrete $\mathrm{LH}$ in response to $\mathrm{GnRH}$ was reduced when the cells were incubated with cortisol, but not when the cells were incubated with ACTH (Li 1987).

\section{Acute stress or elevation of cortisol}

\section{Stress}

There has been little attention paid to the impact of acute stressors on reproduction in female pigs. Anecdotal evidence in gilts suggested that onset of oestrus was delayed on 5 out of 6 occasions when surgery (general anaesthesia for the insertion or repair of jugular catheters) or illness occurred during the follicular phase of the oestrous cycle (Hennessy and Williamson 1983). Nevertheless, this study was designed to investigate the relationships between progesterone, oestrogen and cortisol during the oestrous cycle, but data on ovulation or $\mathrm{LH}$ were not presented. Therefore, it is not clear if these gilts were infertile at this oestrous cycle. It was reported that all gilts became pregnant after mating at their subsequent oestrus (Hennessy and Williamson 1983). There are also reports of stimulatory effects of acute stress on some aspects of reproduction in some species (Turner et al. 2002). Detailed studies of this nature have not been conducted in pigs, however, transport of female pigs advanced onset of puberty (Hughes 1982). 


\section{Cortisol}

There is also a scarcity of data on the effects of acute elevations of cortisol on reproduction in female pigs. Nevertheless, infusion of cortisol into prepubertal gilts for one hour reduced the $\mathrm{LH}$ response to an injection of exogenous $\mathrm{GnRH}$ in comparison to gilts infused with saline and injected with GnRH (Pearce et al. 1988). In the absence of exogenous GnRH, the one-hour cortisol infusion increased endogenous secretion of $\mathrm{LH}$ (Pearce et al. 1988). However, these results do not provide insight as to whether or not fertility would have been affected in post-pubertal pigs by such a treatment with cortisol.

\section{Repeated acute stress or elevation of cortisol}

Stress

If reproduction can be impaired by an acute stress occurring at a critical time during the series of endocrine events that induce oestrus and ovulation, the likelihood of acute stress occurring at a critical time would be markedly increased if acute stress occurred repeatedly. Consequently, it might be expected that reproduction in female pigs would be impaired following exposure to repeated acute stress. We conducted two studies to specifically test this hypothesis.

In one study, gilts were introduced twice daily to a pen containing a mature boar for about 13 days prior to oestrus (Turner et al. 1998a). Plasma concentrations of cortisol increased in the gilts introduced to a boar, but were not significantly elevated in gilts, which had pressure applied to the back twice daily during fence-line exposure to boars (Turner et al. 1998a). Despite cortisol being higher in the gilts that were introduced to boars, the length of the oestrous cycle was reduced and ovulation rate was increased in these gilts. There were no differences between the groups in duration of oestrus, conception rate, fertilisation or embryo viability. Clearly, exposure to this repeated acute stressor did not impair reproduction. It is possible that the stimulatory effects of exposure to boars were due to the direct physical contact between gilts and boars in this treatment because this permitted a high level of exposure of gilts to the behaviour of the boar and/or the visual, auditory, olfactory and tactile stimuli that are known to be provided by the boar (Signoret 1970; Tilbrook and Hemsworth 1990; Barnett et al. 1985). We conducted a subsequent study to further investigate the impact of acute stress on reproduction in a system in which the sexual stimuli provided by the boar did not differ between treatments.

We imposed a negative handling treatment on gilts daily for about 9 days prior to oestrus (Turner et al. 1998b). In this treatment, each pig was confined individually in a pen with the experimenter for 40 seconds. During this time, the experimenter applied brief bouts of electrical stimulation to the pig using a stock-moving prod. Control gilts were confined in the pen with the experimenter, but no electrical stimulation was applied. Negative handling resulted in a substantial elevation of plasma concentrations of cortisol. Nevertheless, none of the reproductive parameters or measures of sexual behaviour including oestrus, ovulation, fertilisation or embryo viability were impaired in the negatively handled gilts compared to control gilts (Turner et al. 1998b).

Collectively, the results of these studies suggest that reproduction in female pigs is resistant to repeated acute stress. Since the stressors used in these studies were severe and frequent, it seems likely that other acute stressors would also have no impact on reproduction in female pigs, even if these occurred during the critical endocrine events of the late follicular phase.

\section{Cortisol}

We have also conducted studies to specifically establish if reproductive processes in female pigs can be impaired by exposure to repeated acute elevation of cortisol. The cortisol treatment regimen resulted in substantial elevations of plasma cortisol. These elevations were 
greater in magnitude, but similar in duration to those that would be expected to follow severe acute stress (Turner et al. 1999a; Turner et al. 1999b).

In one study, gilts received twice daily i.v. injections of cortisol for about 13 days prior to oestrus (Turner et al. 1999b). Despite repeated substantial acute elevations of cortisol in these gilts, the LH surge, oestrus and ovulation did not differ from those of control gilts (Turner et al. $1999 \mathrm{~b})$. These results show that reproduction in these gilts was resistant to repeated acute elevations in plasma cortisol. In a subsequent study, we elevated cortisol to an even greater extent in the absence of oestrogens, and again in the presence of oestradiol to establish if oestradiol would amplify any actions of cortisol on reproductive function (Turner et al. 1999a). We looked for minor perturbations in reproductive function by testing for alterations in the pulsatile secretion of $\mathrm{LH}$ in ovariectomised pigs. Pulsatile secretion of $\mathrm{LH}$ was not impaired by twice daily acute elevation of cortisol for 8 days, in the absence or in the presence of oestradiol, indicating that pulsatile secretion of $\mathrm{LH}$ was resistant to substantial repeated acute elevation of cortisol in the absence and presence of oestradiol.

Thus, based on these results, elevations of cortisol that are likely to occur in response to exposure to acute stress or repeated acute stress are unlikely to suppress reproductive performance in female pigs, even if these occur during the series of endocrine events leading to oestrus and ovulation.

What about acute or repeated acute stress imposed at other times?

While this review has shown that reproduction in female pigs is resistant to acute or repeated acute stress imposed during the series of endocrine events that lead up to oestrus and ovulation, it has not included the effects of acute or repeated acute stress imposed at other times during the reproductive process. It is possible that exposure to acute stress after ovulation around the time of fertilisation, or during early pregnancy around the time of implantation, may impair subsequent reproductive outcomes.

\section{Conclusions}

In the intensive production of pigs, female pigs are often subjected to prolonged, acute or repeated acute stressors. It is, therefore, paramount to understand the impact of such stressors on reproduction. In this manuscript, we have reviewed studies, which confirm that prolonged exposure to stress can, indeed, impair reproductive processes in female pigs. Nevertheless, even under conditions of prolonged stress, reproduction in some female pigs is quite robust, being unaffected by the prolonged stressors imposed. Similarly, while elevation of plasma concentrations of cortisol in a sustained manner for a prolonged period can disrupt reproductive processes in female pigs, there may be some individuals in which reproduction is resistant even to this treatment. When it comes to acute or repeated acute stress or elevation of cortisol, reproduction in female pigs is highly resistant. We considered the impact of acute or repeated acute stress or acute or repeated acute elevation of cortisol imposed during the series of precisely timed endocrine events that lead up to oestrus and ovulation. The studies reviewed show that reproduction in female pigs is unaffected by such treatments. Nevertheless, it is possible that exposure to acute or repeated acute stress after ovulation and/or during early pregnancy may impair reproduction.

We propose modified versions of the hypotheses relating to the impact of prolonged (Fig. 1) and acute (Fig. 2) stress on reproduction in female pigs. When reproduction in female pigs is impaired by prolonged stress, it is possible that cortisol is involved in mediating these effects, although the exact role and sites of action of cortisol are unknown (Turner et al. 2002). In pigs, 
it appears that ACTH does not have direct effects but requires the presence of the adrenal glands to mediate the detrimental effects of $\mathrm{ACTH}$ on reproduction. $\mathrm{CRH}$ and vasopressin may be involved directly (Turner et al. 2002).

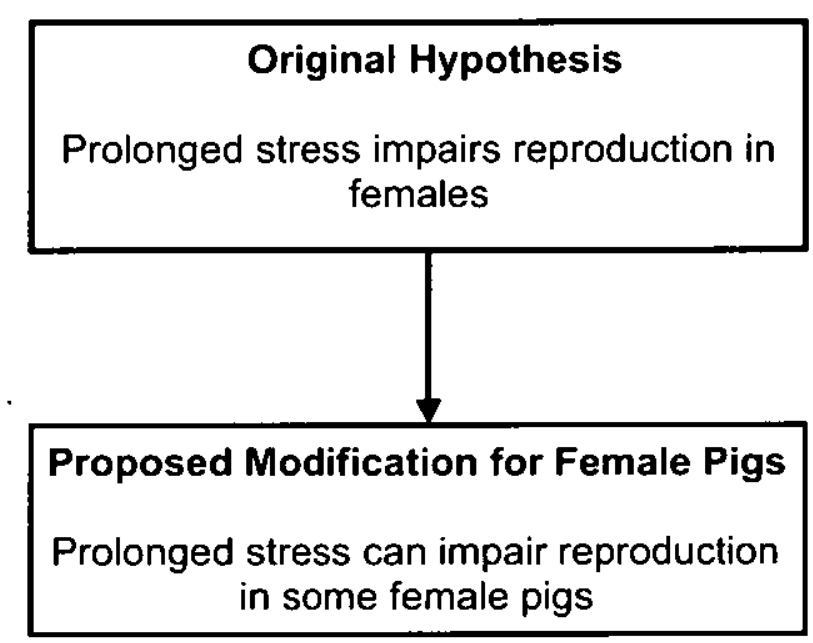

Fig. 1 Proposed modification of the hypothesis relating to the impact of prolonged stress on reproduction in female pigs

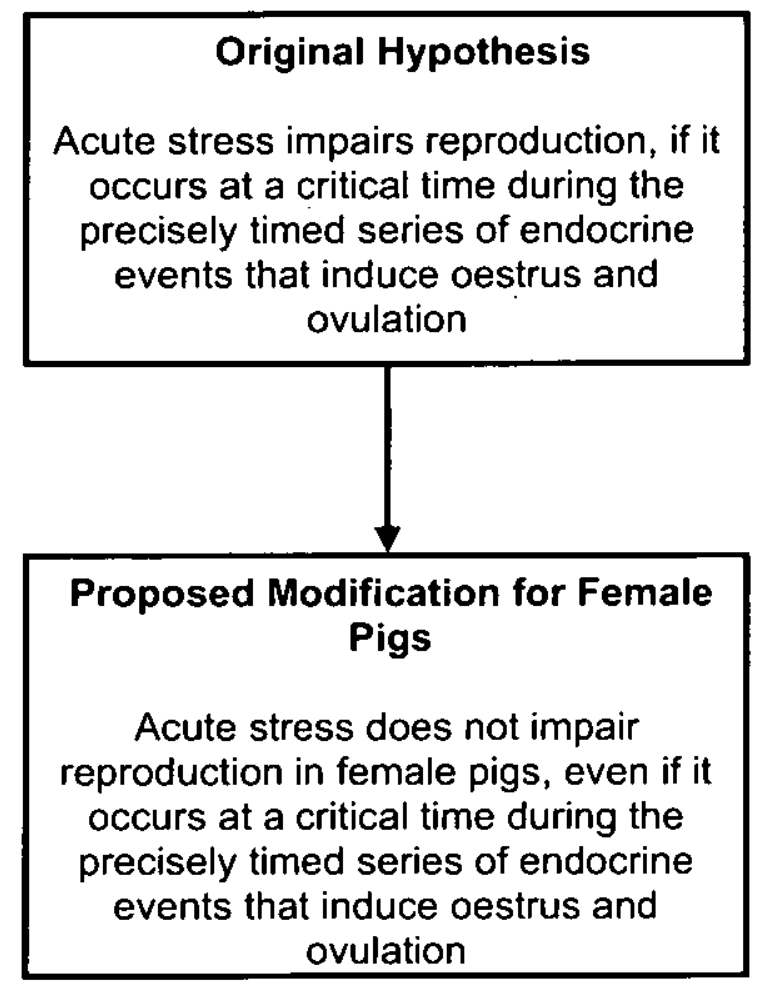

Fig. 2 Proposed modification of the hypothesis relating to the impact of acute stress on reproduction in female pigs 


\section{References}

Antoni FA (1993) Vasopressinergic control of pituitary adrenocorticotropin secretion comes of age. Frontiers in Neuroendocrinology 14, 76-122.

Arey DS, Edwards SA (1998) Factors influencing aggression between sows after mixing and the consequences for welfare and production. Livestock Production Science 56, 61-70.

Barb CR, Kraeling RR, Rampacek GB, Fonda ES, Kiser TE (1982) Inhibition of ovulation and LH secretion in the gilt after treatment with ACTH or hydrocortisone. Journal of Reproduction and fertility 64, 85-92.

Barnett JL, Hemsworth PH (1991) The effects of individual and group housing on sexual-behavior and pregnancy in pigs. Animal Reproduction Science 25. 265-273.

Barnett JL, Hemsworth PH, Cronin GM (1982) The effect of mating on plasma corticosteroids in the female pig and the influence of individual and group penning on this response. Ceneral and Comparative Endocrinology 47, 516-521.

Barnett JL, Hemsworth PH, Cronin GM, Newman EA, McCallum TH, Chilton D (1992) Effects of pen size, partial stalls and method of feeding on welfare-related behavioural and physiological responses of group- housed pigs. Applied Animal Behaviour Science 34, 207-220.

Barnett JL, Winfield CG, Cronin GM, Hemsworth PH, Dewar AM (1985) The effect of individual and group housing on behavioural and physiological responses related to the welfare of pregnant pigs. Applied Animal Behaviour Science 14, 149-161.

Becker BA, Nienaber JA, Christenson RK, Manak RC, DeShazer JA, Hahn CL. (1985) Peripheral concentrations of cortisol as an indicator of stress in the pig. American Journal of Veterinary Research 46, 10341038.

Clarke IJ (1996) Effector mechanisms of the hypothalamus that regulate the anterior pituitary gland. In 'The Autonomic Nervous System'. (Ed. K Unsicker) pp. 45-88. (Harwood: London)

Clarke II, Hemsworth PH, Barnett JL, Tilbrook A] (1992) Stress and reproduction in farm animals. In 'Stress and Reproduction'. (Eds KE Sheppard, JH Boublik, and JW Funder) pp. 239-252. (Serono Symposia Publications, Raven Press: New York)

Close RW, Liptrap RM (1975) Plasma progesterone levels in sows with induced cystic ovarian follicles. Research in Veterinary Science 19, 28-34.

Coubrough RI (1985) Stress and fertility. A review. Onderstepoort.J. Vet.Res. 52, 153-156.

Da Silva JA (1995) Sex hormones, glucocorticoids and autoimmunity: facts and hypotheses. Ann.Rheum. Dis. 54, 6-16.

Dalin AM, Magnusson U, Haggendal J, Nyberg L (1993a) The effect of thiopentone-sodium anesthesia and surgery, relocation, grouping, and hydrocortisone treatment on the blood levels of cortisol, corticosteroidbinding globulin, and catecholamines in pigs. fournal of Animal Science 71, 1902-1909.
Dalin AM, Magnusson U, Haggendal J, Nyberg L (1993b) The effect of transport stress on plasma-levels of catecholamines, cortisol, corticosteroid-binding globulin, blood-cell count, and lymphocyte-proliferation in pigs. Acta Veterinaria Scandinavica 34, 59-68.

Dallman MF, Akana SF, Scribner KA, Bradbury MJ, Walker C-D, Strack AM, Cascio CS (1992) Stress, feedback and facilitation in the hypothalamo-pituitary-adrenal axis. Journal of Neuroendocrinology 4, 517-526.

Dobson H, Smith RF (1995) Stress and reproduction in farm animals. Journal of Reproduction and Fertility Supplement 49, 451-461.

Esbenshade KL, Paterson AM, Day BN (1983) Glucocorticoids and estrus in swine. I. The relationship between triamcinolone acetonide and estrogen in the expression of estrus in gilts. Journal of Animal Science $56,460-465$.

Esbenshade KL, Ziecik Al, Britt JH (1990) Regulation and action of gonadotrophins in pigs. I.Reprod.Fertil.Suppl. 40, 19-32.

Estienne MJ, Barb CR, Kesner JS, Kraeling RR, Rampacek GB (1991) Luteinizing-hormone secretion in hypophyseal stalk-transected gilts given hydrocortisone acetate and pulsatile gonadotropin-releasing-hormone. Domestic Animal Endocrinology 8, 407-414.

Farmer C, Dubreuil P, Couture Y, Brazeau P, Petitclerc $D$ (1991) Hormonal changes following an acute stress in control and somatostatin-immunized pigs. Domestic.Animal.Endocrinology 8, 527-536.

Fonda ES, Rampacek GB, Kraeling RR (1984) The effect of adrenocorticotropin or hydrocortisone on serum luteinizing hormone concentrations after adrenalectomy and/or ovariectomy in the prepuberal gilt. Endocrinology 114, 268-273.

Frautschy SA, Gaon D, Liptrap RM (1989) Effect of dexamethasone on gonadotrophin secretion in the gonadectomized sow and boar. Canadian lournal of Veterinary Research 53, 490-492.

Frautschy SA, Liptrap RM (1988) Anovulation and plasma hormone concentrations after administration of dexamethasone during the middle of the luteal phase in sows undergoing estrous cycles. American journal of Veterinary Research 49, 1270-1275.

Goldstein DS (1987) Stress-induced activation of the sympathetic nervous system. In 'Neuroendocrinology of Stress'. (Ed. A Grossman) pp. 253-278. (Bailliere Tindall: London)

Harbuz MS, Lightman SL (1992) Stress and the hypothalamo-pituitary-adrenal axis: acute, chronic and immunological activation. Journal of Endocrinotogy 134, 327-339.

Heller H (1960) Antidiuretic hormones of the neurohypophysis. Acta Endocrinologica 34 (Suppl. 50), 5156.

Hemsworth PH, Barnett JL, Hansen C (1986a) The influence of handling by humans on the behaviour, reproduction and corticosteroids of male and female pigs. Applied Animal Behaviour Science 15, 303-314. 
Hemsworth PH, Barnett JL, Hansen C (1987) The influence of inconsistent handling by humans on the behaviour, growth and corticosteroids of young pigs. Applied Animal Behaviour Science 17, 245-252.

Hemsworth PH, Barnett JL, Hansen C, Winfield CG (1986b) Effect of social environment on welfare status and sexual behaviour of female pigs. II. Effects of space allowance. Applied Animal Behaviour Science 16, 259-267.

Hennessy DP, Williamson P (1983) The effects of stress and of ACTH administration on hormone profiles, estrus and ovulation in pigs. Theriogenology 20, 1326.

Hughes PE (1982) Factors affecting the natural attainment of puberty in the gilt. In 'Control of Pig Reproduction'. (Eds DJA Cole and GR Foxcroft) pp. 117. 138. (Butterworth: London)

Janssens CJ, Helmond FA, Wiegant VM (1994) increased cortisol response to exogenous adrenocorticotropic hormone in chronically stressed pigs: influence of housing conditions. Journal of Animal Science 72, 1771-1777.

Janssens CJJG, Helmond FA, Loyens IWS, Schouten WGP, Wiegant VM (1995a) Chronic stress increases the opioid-mediated inhibition of the pituitary-adrenocortical response to acute stress in pigs. Endocrinology 136, 1468-1473.

Janssens CJJG, Helmond FA, Wiegant VM (1995b) The effect of chronic stress on plasma cortisol concentrations in cyclic female pigs depends on the time of day. Domestic Animal Endocrinology 12, 167-177.

Kineman RD, Leshin LS, Crim JW, Rampacek GB, Kraeling RR (1988) Localization of luteinizing hormone-releasing hormone in the forebrain of the pig. Biology of Reproduction 39, 665-672.

Kraeling RR, Barb CR (1990) Hypothalamic control of gonadotrophin and prolactin secretion in pigs. I.Reprod.Fertil.Suppl. 40, 3-17.

Li PS (1987) Effect of cortisol or adrenocorticotropic hormone on luteinizing hormone secretion by pig pituitary cells in vitro. Life Sciences 41, 2493-2501.

Liptrap RM (1970) Effect of corticotrophin and corticosteroids on oestrus, ovulation and oestrogen excretion in the sow. J.Endocrinol. 47, 197-205.

Liptrap RM (1973) Oestrogen excretion by sows with induced cystic ovarian follicles. Research in Veterinary Science 15, 215-219.

Liptrap RM (1993) Stress and reproduction in domestic animals. Ann.N.Y.Acad.Sci. 697, 275-284.

McGlone IJ, Salak JL, Lumpkin EA, Nicholson RI, Gibson M, Norman RL (1993) Shipping stress and social status effects on pig performance, plasma cortisol, natural killer cell activity, and leukocyte numbers. Journal.of.Animal.Science 71, 888-896.

Minton JE (1994) Function of the hypothalamic-pituitary-adrenal axis and the sympathetic nervous system in models of acute stress in domestic farm animals. Journal of Animal Science 72, 1891-1898.

Minton JE, Parsons KM (1993) Adrenocorticotropic hormone and cortisol response to corticotropin- releas- ing factor and lysine vasopressin in pigs. Journal of Animal Science 71, 724-729.

Moberg GP (1985a) Biological Response to Stress: Key to Assessment of Animal Well-Being? In 'Animal Stress'. (Ed. GP Moberg) pp. 27-49. (Williams \& Wilkins: Baltimore)

Moberg GP (1985b) Influence of stress on reproduction: measure of well-being. In 'Animal Stress'. (Ed. GP Moberg) pp. 245-267. (Williams \& Wilkins: Baltimore)

Moberg GP (1987) Influence of the adrenal axis upon the gonads. In 'Oxford reviews of reproductive biology'. (Ed. JR Clarke) pp. 456-496. (Clarendon Press: Oxford)

Moberg GP (1991) How behavioral stress disrupts the endocrine control of reproduction in domestic animals. Journal of Dairy Science 74, 304-311.

Munck A, Guyre PM, Holbrook NJ (1984) Physiological functions of glucocorticoids in stress and their relation to pharmacological actions. Endocrine Reviews 5, 25-44.

Paterson AM, Cantley TC, Esbenshade KL, Day BN (1983) Glucocorticoids and estrus in swine. II. Plasma concentrations of estradiol- 17 beta, glucocorticoids and luteinizing hormone in ovariectomized gilts given estradiol benzoate and triamcinolone acetonide. Journal of Animal Science 56, 466-470.

Pearce GP, Paterson AM, Hughes PE (1988) Effect of short-term elevations in plasma cortisol concentration on LH secretion in prepubertal gilts. I.Reprod.Feril. 83, 413-418.

Rushen J, Ladewig J (1991) Stress-induced hypoalgesia and opioid inhibition of pigs' responses to restraint. Physiology \& Behavior 50, 1093-1096.

Sapolsky RM, Romero LM, Munck AU (2000) How do glucocorticoids influence stress responses? Integrating permissive, suppressive, stimulatory, and preparative actions. Endocrine Reviews 21, 55-89.

Sawchenko PE, Imaki T, Vale W (1992) Colocalization of neuroactive substances in the endocrine hypothalamus. Ciba Foundation Symposia 168, 16-42.

Schilling E, von Rechenberg W (1973) Funktion der nebennierenrinde und ovulationsprozeB beim schwein. Zentralblatt.Fur.Veterinarmedizin.-.Reihe.A. 20, 705-717.

Scholten JA, Liptrap RM (1978) A role for the adrenal cortex in the onset of cystic ovarian follicles in the sow. Can.J.Comp.Med. 42, 525-533.

Signoret JP (1970) Reproductive behaviour of pigs. Journal of Reproduction and Fertility Supplement 11, 105117.

Soede NM, Helmond FA, Schouten WP, Kemp B (1997) Oestrus, ovulation and peri-ovulatory hormone profiles in tethered and loose-housed sows. Animal Reproduction Science 46, 133-148.

Tilbrook AJ, Hemsworth PH (1990) Detection of oestrus in gilts housed adjacent or opposite to boars or exposed to exogenous boar stimuli. Applied Animal Behaviour Science 28, 233-245.

Tilbrook AJ, Turner Al, Clarke If (2000) Effects of stress on reproduction in non-rodent manmals: the role of 
glucocorticoids and sex differences. Reviews of Reproduction 5, 105-113.

Tilbrook AJ, Turner Al, Clarke I] (2002) Stress and reproduction: central mechanisms and sex differences in non-rodent species. Stress 5, 83-100.

Torpy DI, Chrousos GP (1996) The three-way interactions between the hypothalamic-pituitary-adrenal and gonadal axes and the immune system. Baillieres.Clinical.Rheumatology. 10, 181-198.

Turner Al, Hemsworth PH, Canny BJ, Tilbrook Al (1999a) Inhibition of the secretion of L.H in ovariectomised pigs by sustained but not repeated acute elevation of cortisol in the absence but not the presence of oestradiol. Journal of Endocrinology 163, 477-486.

Turner Al, Hemsworth PH, Canny B], Tilbrook A] (1999b) Sustained but not repeated acute elevation of cortisol impaired the luteinizing hormone surge, estrus, and ovulation in gilts. Biology of Reproduction 61, 614-620.

Turner Al, Hemsworth PH, Hughes PE, Canny BJ, Tilbrook A] (1998a) The effect of repeated boar exposure on cortisol secretion and reproduction in gilts. Animal Reproduction Science 51, 143-154.

Turner Al, Hemsworth PH, Hughes PE, Tilbrook A] (1998b) Repeated acute activation of the hypothalamo-pituitary adrenal axis prior to and during estrus did not affect reproductive performance in gilts. Biology of Reproduction 58, 1458-1462.
Turner Al, Hemsworth PH, Tilbrook AJ (2002) Susceptibility of reproduction in female pigs to impairment by stress and the role of the hypothalamo-pituitaryadrenal axis. Reproduction Fertility and Development 14, 377-391.

Udelsman R, Holbrook NJ (1994) Endocrine and molecular responses to surgical stress. Current Problems in Surgery 31, 653-720.

Varley MA, Stedman R (1994) Stress and reproduction. In 'Principles in Pig Science'. (Eds DJ Cole, I Wiseman, and MA Varley) pp. 277-296. (Nottingham University Press: Loughborough, Leicestershire)

Veum TL, Ellersieck MR, Durham TL, McVickers WR, McWilliams SN, Lasley JF (1979) Response of stresssusceptible and stress-resistant Hampshire pigs to electrical stress. I. Physiological and biochemical effects. Journal.of.Animal.Science 48, 446-452.

von Borell E (1995) Neuroendocrine integration of stress and significance of stress for the performance of farm animals. Applied Animal Behaviour Science 44, 219. 227.

Zeleznik AJ, Hillier SG (1996) The ovary: Endocrine function. In 'Scientific Essentials of Reproductive Medicine'. (Eds SC Hillier, HC Kitchener, and JP Neilson) pp. 133-146. (Saunders: London) 